\title{
Sirt1 Mediates Improvement in Cognitive Defects Induced by Focal Cerebral Ischemia Following Hyperbaric Oxygen Preconditioning in Rats
}

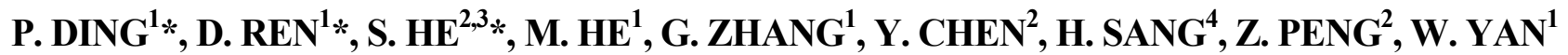 \\ *These authors contributed equally to this work. \\ ${ }^{1}$ Department of Anesthesiology, Gansu Provincial Hospital, Lanzhou, China, ${ }^{2}$ Department of \\ Psychiatry, Xijing Hospital, Fourth Military Medical University, Xi'an, China, ${ }^{3}$ Department of \\ Rehabilitation, Tangdu Hospital, Fourth Military Medical University, Xi'an, China, ${ }^{4}$ Department of \\ Anesthesiology, Xijing Hospital, Fourth Military Medical University, Xi'an, China
}

Received November 1, 2016

Accepted June 2, 2017

On-line September 22, 2017

\section{Summary}

Hyperbaric oxygen preconditioning (HBO-PC) has been proposed as a safe and practical approach for neuroprotection in ischemic stroke. However, it is not known whether HPO-PC can improve cognitive deficits induced by cerebral ischemia, and the mechanistic basis for any beneficial effects remains unclear. We addressed this in the present study using rats subjected to middle cerebral artery occlusion (MCAO) as an ischemic stroke model following HBO-PC. Cognitive function and expression of phosphorylated neurofilament heavy polypeptide (pNF-H) and doublecortin (DCX) in the hippocampus were evaluated 14 days after reperfusion and after short interfering RNA-mediated knockdown of sirtuin1 (Sirt1). HBO-PC increased pNF-H and DCX expression and mitigated cognitive deficits in MCAO rats. However, these effects were abolished by Sirt1 knockdown. Our results suggest that $\mathrm{HBO}-\mathrm{PC}$ can protect the brain from injury caused by ischemia-reperfusion and that Sirt1 is a potential molecular target for therapeutic approaches designed to minimize cognitive deficits caused by cerebral ischemia.

\section{Key words}

$\mathrm{HBO}-\mathrm{PC} \bullet$ Sirt1 $\bullet$ MCAO $\bullet$ Cognitive defects

\section{Corresponding authors}

Z. Peng, Department of Psychiatry, Xijing Hospital, Fourth Military Medical University, 127 Changle Road, Xi'an, Shaanxi, 710032, China. Fax: (+86)-29-83293951. E-mail: pengzhengwu1446@ 163.com and W. Yan, Department of Anesthesiology, Gansu
Provincial Hospital, Lanzhou, 730000, China. E-mail: gsywj2008@hotmail.com

\section{Introduction}

Stroke is a leading cause of morbidity and mortality worldwide (Russo et al. 2011) that can lead to severe neurological disabilities in adults. In addition to motor and sensory disturbances (Meyer et al. 2015), stroke is associated with cognitive deficits involving spatial learning and memory acquisition and retention (Massa et al. 2015, Jafari et al. 2016, Kraft et al. 2015). Further investigation of the underlying pathogenesis mechanism of stroke and development novel treatment strategies might be benefit for the therapy of stroke.

During ischemia and reperfusion, elevated levels of reactive oxygen species activate diverse signaling pathways, resulting in oxidative stress (Niizuma et al. 2009, Deb et al. 2010) and inflammation (Minami et al. 2006); systemic administration of antioxidants or anti-inflammatory agents can improve ischemic neurological damage, decrease infarct size, prevent hemorrhagic transformation, and improve neurological and cognitive functions (Li et al. 2011a, Du et al. 2012, Qiao et al. 2012, Kure et al. 2016). Thus, oxidative stress and inflammation are major contributors to post-ischemic injury (Chan 1996, Amantea et al. 2009, Jin et al. 2010, Chen et al. 2011). 
Hyperbaric oxygen preconditioning (HBO-PC) has been proposed as a safe and practical approach for neuroprotection against ischemic stroke (Xiong et al. 2000). HBO-PC was shown to decrease infarct size, prevent hemorrhagic transformation, and improve neurological function in hyperglycemic middle cerebral artery occlusion (MCAO) rats (Soejima et al. 2013, Bian et al. 2015). Previous studies showed that sirtuin1 (Sirt1) which is involved in memory formation, brain plasticity, axonal protection, and neuronal survival (Kim et al. 2007, Gao et al. 2010) mediates HBO-PC-associated ischemic tolerance in rat brain (Yan et al. 2013). However, the outcomes of HBO-PC on the cognition deficits as well as the precise role of Sirt1 in neuroprotection are not well understood.

We addressed this in the present study using a rat model of ischemic stroke in which the animals were subjected to HBO-PC prior to MCAO; then the cognitive function, changes in hippocampal structure, and the expression of phosphorylated neurofilament heavy polypeptide (pNF-H) and doublecortin (DCX) were evaluated 14 days later. We also examined the role of Sirt1 by short interfering (si) RNA-mediated knockdown of Sirtl transcript.

\section{Materials and Methods}

\section{Animals}

Animal experiments were approved by the Ethics Committee for Animal Experimentation and were carried out in accordance with the National Institutes of Health (NIH) Guidelines for Care and Use of the Laboratory Animals (Bethesda, MD, USA). Male Sprague Dawley (SD) rats weighing 280-320 g were obtained from the animal center of Fourth Military Medical University. Four rats were housed per cage in an air-conditioned room (at $22 \pm 1{ }^{\circ} \mathrm{C}$ ) with $50-55 \%$ relative humidity under a 12 -h light/dark cycle and provided with food and water ad libitum.

\section{Experiment 1}

After 7 days of acclimatization, rats were randomly assigned to one of the following four groups $(\mathrm{n}=12$ each): sham, HBO, MCAO, and HBO + MCAO. Freezing behavior was evaluated 14 days after MCAO; the animals were then sacrificed, and hippocampal expression of pNF-H and DCX was evaluated by immunohistochemistry and Western blotting.
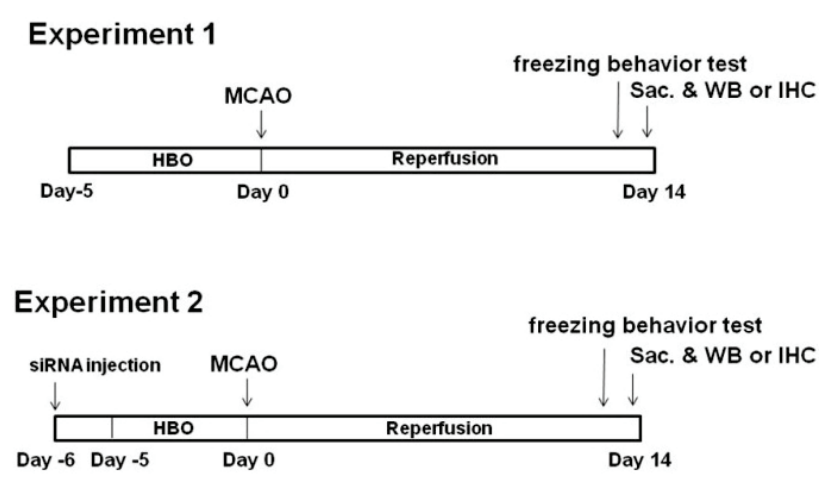

Fig. 1. Schematic diagram detailing the time course of treatment.

\section{Experiment 2}

After acclimatization, rats were randomly assigned to four groups ( $\mathrm{n}=12$ each): siRNA-C, HBO + siRNA-C, siRNA-Sirt1, and HBO + siRNA-Sirt1. Rats in the siRNA-C and $\mathrm{HBO}+$ siRNA-C groups were transfected with control siRNA, while those in the siRNA-Sirt1 and HBO + siRNA-Sirt1 groups were transfected with Sirt1-siRNA; the animals then underwent sham HBO or HBO treatment $24 \mathrm{~h}$ later and were subjected to MCAO $24 \mathrm{~h}$ after the last HBO treatment. Freezing behavior and hippocampal expression of pNF-H and DCX were evaluated 14 days after MCAO (Table 1).

Table 1. The description of the abbreviation of each group.

\section{Group abbreviation Treatments}

SiRNA-C

$\mathrm{HBO}+$ siRNA-C

siRNA-Sirt1

HBO + siRNA-Sirt1
Transfected with control siRNA then underwent sham HBO treatment and subjected to MCAO

Transfected with control siRNA then underwent HBO treatment and subjected to MCAO Transfected with Sirt1-siRNA then underwent sham HBO treatment and subjected to MCAO

Transfected with Sirt1-siRNA then underwent HBO treatment and subjected to MCAO 


\section{$H B O-P C$}

The protocol for HBO-PC is described in our previous studies (Yan et al. 2011, Yan et al. 2013). Briefly, rats were exposed $\mathrm{HBO}$ at 2.5 ATA in $100 \%$ oxygen for $1 \mathrm{~h}$ daily for 5 consecutive days in a hyperbaric chamber (model no. NG90-IIC; Yantai Binglun, Yantai, China) maintained between $23{ }^{\circ} \mathrm{C}$ and $26^{\circ} \mathrm{C}$. Compression and decompression were carried out at a rate of $0.2 \mathrm{~atm} / \mathrm{min}$. The total time that animals spent within the chamber was approximately $1 \mathrm{~h}+$ compression $(12.5 \mathrm{~min})+$ decompression $(12.5 \mathrm{~min})$ and nearly 20 rats were exposed to HBO during one session and oxygen concentration was monitored with a calibrated oximeter. Accumulated $\mathrm{CO}_{2}$ was absorbed by calcium carbonate crystals. The exposure was initiated at the same time each day in order to minimize the impact of biological rhythms. Rats under normobaric conditions in the same chamber served as controls.

\section{Induction of transient focal cerebral ischemia}

Focal cerebral ischemia was induced as described in previous studies using the method of right MCAO with an intraluminal filament (Wang et al. 2009). Briefly, rats were anesthetized by intraperitoneal injection of $40 \mathrm{mg} / \mathrm{kg}$ sodium pentobarbital and placed on a heating pad that maintained their body temperature. After making a midline neck incision, the right common and external carotid arteries were exposed and proximally ligated. A 3-0 rounded-tip nylon monofilament suture (1893G; Ethicon, Somerville, NJ, USA) was advanced from the common carotid artery incision just below the carotid bifurcation up to the internal carotid artery until regional cerebral blood flow was reduced to $<16 \%$ of the baseline level, thereby occluding the base of the anterior and middle cerebral and posterior communicating arteries. After $2 \mathrm{~h}$, the filament was slowly withdrawn and blood flow was restored to $\geq 75 \%$ of baseline. Cerebral blood flow was monitored by laser Doppler flowmetry (PeriFlux System 5000; Perimed, Järälla, Sweden) in the ipsilateral cortex $(2 \mathrm{~mm}$ posterior and $5 \mathrm{~mm}$ lateral to bregma) and rectal temperature was monitored (90303B; Spacelabs Healthcare, Snoqualmie, WA, USA) and maintained between $37.0^{\circ} \mathrm{C}$ and $37.5^{\circ} \mathrm{C}$. Sham rats underwent the same surgical procedure but without MCAO. There were no significant differences between cerebral blood flow values before, during and after MCAO between MCAO and HBO + MCAO group, and among siRNA-C, HBO + siRNA-C, siRNA-Sirt1 and $\mathrm{HBO}+$ siRNA-Sirt1 as well (Table 2).

Table 2. The cerebral blood flow values (PU) of each group.

\begin{tabular}{lccc}
\hline Group & Before MCAO & During MCAO & After MCAO \\
\hline MCAO & $140.00 \pm 8.59$ & $20.30 \pm 1.24$ & $109.20 \pm 6.70$ \\
HBO + MCAO & $142.25 \pm 10.74$ & $20.63 \pm 1.56$ & $110.96 \pm 8.38$ \\
siRNA-C & $141.38 \pm 8.35$ & $20.50 \pm 1.21$ & $110.27 \pm 6.51$ \\
HBO + siRNA-C & $143.50 \pm 11.60$ & $20.81 \pm 1.68$ & $111.93 \pm 9.05$ \\
siRNA-Sirt1 & $152.25 \pm 12.33$ & $22.08 \pm 1.79$ & $118.76 \pm 9.61$ \\
HBO + siRNA-Sirt1 & $144.13 \pm 12.05$ & $20.90 \pm 1.75$ & $112.42 \pm 9.40$ \\
\hline
\end{tabular}

\section{SiRNA transfection in rat brain}

In vivo siRNA transfection in rat brain was carried out as previously described (Chen et al. 2009, Xue et al. 2016). Briefly, rats were anesthetized with $10 \%$ chloral hydrate, and a stainless steel cannula was stereotaxically implanted into the cerebral ventricle. The stereotaxic coordinates were $1.8 \mathrm{~mm}$ posterior and $1.5 \mathrm{~mm}$ lateral to bregma at a depth of $4.0 \mathrm{~mm}$ from the skull surface. A $10-\mu l$ volume of $50 \mathrm{nmol} / 1$ Sirt1 siRNA (sc-108043) or control siRNA (sc-37007) (both from Santa Cruz Biotechnology, Santa Cruz, CA, USA) was delivered into the lateral ventricle.

\section{Assessment of freezing behavior}

The experiment was performed as previously described (Nie et al. 2014) in the shock chamber and neutral test contexts. For shock application, rats were placed in the shock chamber, and after $196 \mathrm{~s}$, a single 4-s scrambled electric shock was delivered in the form of a $1-\mathrm{mA}$ current to the feet through a metal grid, which produced signs of pain (jumping or vocalization). Stressed rats remained in the shock chamber for another $60 \mathrm{~s}$ before being returned to their home cage. To assess conditioned fear, rats were re-exposed to the shock chamber for $3 \mathrm{~min}$ without tone presentation or further 
shock application and then immediately returned to their home cage. To test for fear sensitization, animals were placed in the neutral test chamber and after $3 \mathrm{~min}$ a neutral tone $(80 \mathrm{~dB}, 9 \mathrm{kHz})$ was presented for $3 \mathrm{~min}$. After another $60 \mathrm{~s}$, rats were returned to their home cages. The activity of each rat was recorded and analyzed using the Freezing Scan system (Clever Sys, Reston, VA, USA).

\section{Western blotting}

The hippocampus was dissected and lysed with sodium dodecyl sulfate-polyacrylamide gel electrophoresis (SDS-PAGE) sample buffer composed of $62.5 \mathrm{mM}$ Tris-HCl, $2 \% \mathrm{w} / \mathrm{v}$ SDS, $10 \%$ glycerol, $50 \mathrm{mM}$ dithiothreitol, and $0.1 \% \mathrm{w} / \mathrm{v}$ Bromophenol Blue. After homogenization, tissue extracts were centrifuged at $12,000 \times \mathrm{g}$ for $10 \mathrm{~min}$. The protein concentration in the supernatant was determined with a bicinchoninic acid protein assay kit (Pierce, Rockford, IL, USA). Aliquots of lysate with loading buffer (Beyotime Institute of Biotechnology, Beijing, China) were boiled for $10 \mathrm{~min}$ and then cooled to room temperature, and equal amounts of protein $(20-40 \mathrm{mg}$ ) were separated by SDS-PAGE and transferred to a polyvinylidene difluoride membrane (Millipore, Billerica, MA, USA) that was blocked with $5 \%$ skim milk in Tris-buffered saline and then incubated overnight at $4{ }^{\circ} \mathrm{C}$ with the following primary antibodies: rabbit anti-DCX (1:500, ab18723; Abcam, Cambridge, UK), mouse anti-pNF-H (1:800, ab7795; Abcam), and mouse anti- $\beta$-actin (1:10,000, A5441; Sigma-Aldrich, St. Louis, MO, USA). After washing, the membrane was incubated with the appropriate horseradish peroxidaseconjugated IgG for $1 \mathrm{~h}$ at room temperature. Immunoreactivity was visualized on X-ray film using Super ECL Plus detection reagent (34077; Thermo Fisher Scientific, Waltham, MA, USA). Band intensity was normalized to $\beta$-actin level using ImageJ software (NIH).

\section{Immunohistochemistry}

Immediately after behavioral testing, half of the rats from each group were deeply anesthetized with chloral hydrate and perfused through the ascending aorta with $0.1 \mathrm{M}$ phosphate buffered saline (PBS) followed by $4 \%$ paraformaldehyde in PBS. The brains were removed and post-fixed in the same solution for $1 \mathrm{~h}$, then dehydrated in $25 \%$ sucrose in PBS at $4{ }^{\circ} \mathrm{C}$ until saturation. Serial coronal sections were cut at a thickness of $16 \mu \mathrm{m}$ on a sliding microtome (CM3050 S; Leica, Buffalo Grove, IL, USA) and mounted on gelatinized slides. Three sets of sections from each rat brain were used for immunofluorescence labeling. Sections were incubated for $24 \mathrm{~h}$ at room temperature with a primary antibody against pNF-H (1:500) or DCX (1:300) in blocking solution composed of $0.2 \%$ Triton X-100 and $5 \%$ bovine serum albumin (Sigma-Aldrich) in PBS. Sections were then incubated with Alexa Fluor 488 donkey anti-rat $(1: 1,000$, ab150073; Abcam) or antimouse (1:1,000, ab150105; Abcam) IgG (Invitrogen, Carlsbad, CA, USA) at room temperature for $3 \mathrm{~h}$. Every sixth section throughout the hippocampus was processed and visualized under a laser scanning confocal microscope (FV-1000, Olympus), and the integral optical density (IOD) of pNF-H or DCX immunofluorescence in the images was analyzed with Image-Pro plus software (Media Cybernetics, Rockville, MD, USA).

\section{Statistical analysis}

Data were analyzed with SPSS v.16.0 software (SPSS Inc., Chicago, IL, USA) and are presented as mean \pm SEM. Differences between groups were evaluated by one-way analysis of variance and a post hoc least significant difference (LSD) test. Differences were considered significant at $P<0.05$.

\section{Results}

HBO-PC reduces cognitive deficits induced by cerebral ischemia

Significant differences were observed between groups for both conditioned fear $\left(F_{3,21}=9.639, P<0.01\right)$ and sensitized fear $\left(F_{3,26}=13.08, \quad P<0.01\right) \quad$ (Fig. 2). Multiple comparisons revealed that MCAO caused
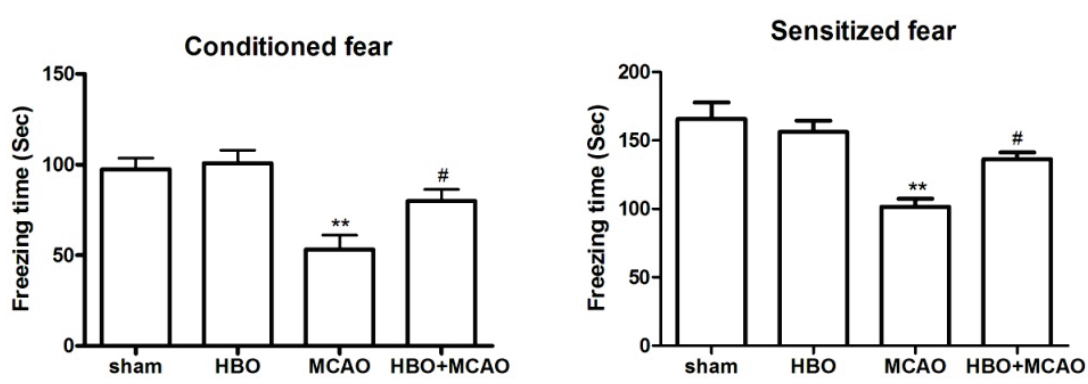

Fig. 2. HBO-PC improves cognitive behavior in the conditioned fear test. Freezing time for conditioned fear (left panel) and sensitized fear (right panel) in each group. ** $P<0.01$ vs. sham, ${ }^{\#} P<0.05$ vs. MCAO. 
cognitive deficits (i.e. reduced freezing time in both conditioned and sensitized fear) as compared to sham treatment $(P<0.01)$, whereas HBO-PC abolished this effect $(P<0.05$ vs. MCAO). Meanwhile, there is also significant difference between $\mathrm{HBO}+\mathrm{MCAO}$ and sham in the freezing time in both conditioned and sensitized fear test $(P<0.05)$. Suggesting the treatment of HBO-PC could not fully improve the cognitive deficits induced by MCAO.
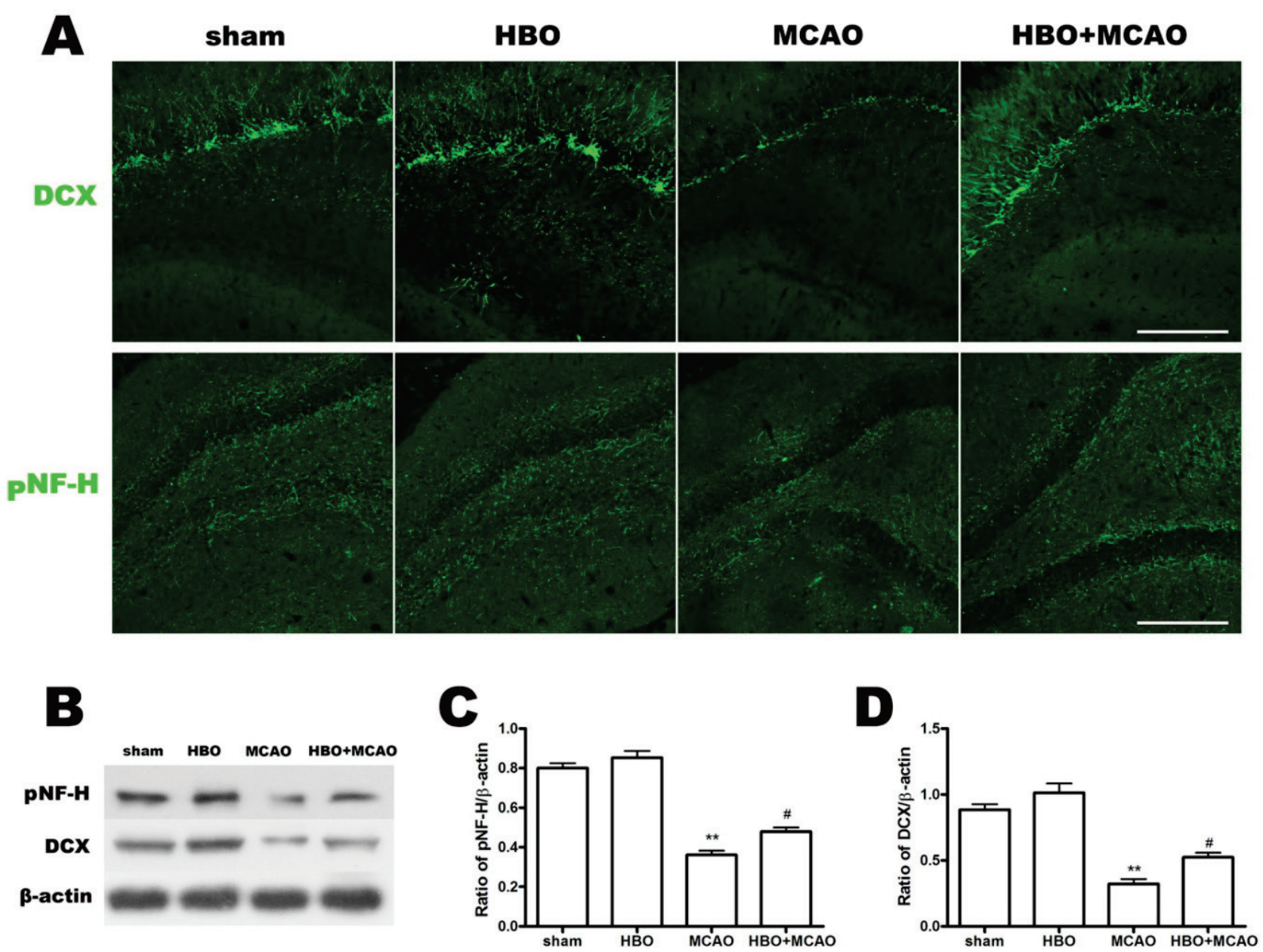

Fig. 3. HBO-PC increases pNF-H and DCX expression in the hippocampus of the ischemic brain. Representative photomicrographs of pNF-H and DCX expression in each group as determined by immunolabeling (A) and Western blot analysis (B). Quantitative analysis of pNF-H (C) and DCX (D) expression levels. ${ }^{* *} P<0.01$ vs. sham, ${ }^{*} P<0.05$ vs. MCAO. Bar: $200 \mu \mathrm{m}$.

HBO-PC restores $p N F-H$ and DCX expression in the hippocampus following ischemia

The expression of $\mathrm{pNF}-\mathrm{H}$ and DCX in the hippocampus differed between the four groups, as determined by immunohistochemistry (pNF-H: $F_{3,16}=90.05, P<0.01$ and DCX: $\left.F_{3,16}=49.65, P<0.01\right)$ and Western blotting (pNF-H: $F_{3,16}=88.27, P<0.01$ and DCX: $F_{3,16}=44.94, P<0.01$ ) (Fig. 3 and data not shown). A post hoc analysis revealed that pNF-H and DCX levels were significantly lower in the MCAO as compared to the sham group $(P<0.01)$, effects that were mitigated by HBO-PC.
Sirt1 knockdown prevents $H B O-P C$-induced cognitive improvement

Conditioned fear $\left(F_{3,21}=9.204, \quad P<0.01\right)$ and sensitized fear $\left(F_{3,23}=10.65, P<0.01\right)$ responses differed between the four groups (Fig. 4). siRNA-mediated knockdown of Sirtl abrogated the improvements in freezing time for both conditioned and sensitized fear induced by HBO-PC $(P<0.05, \mathrm{HBO}+$ siRNA-C vs. HBO + siRNA-Sirt1), whereas control siRNA treatment had no effect (i.e. there was no difference between siRNA-Sirt1 and $\mathrm{HBO}+$ siRNA-Sirt1 groups in terms of freezing time for both conditioned and sensitized fear; $P>0.05$ ). 

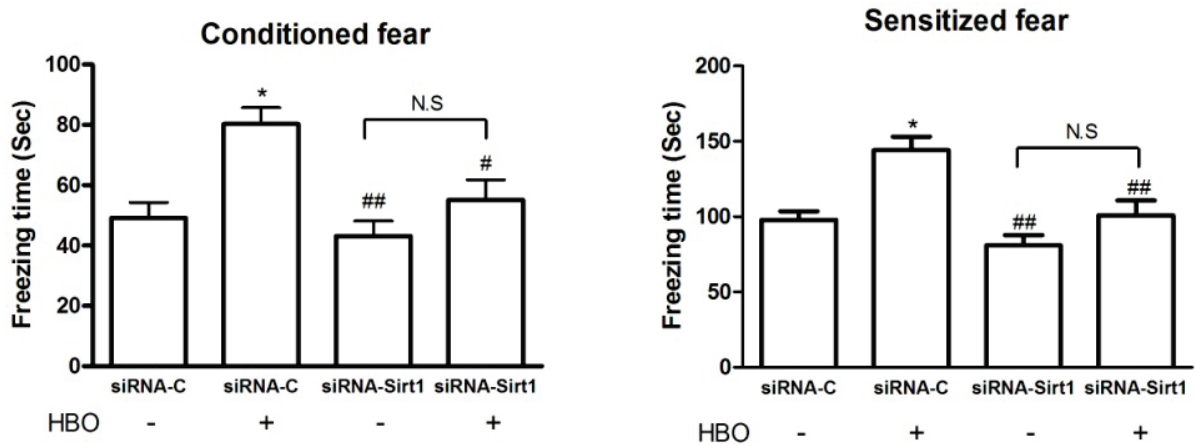

Fig. 4. Sirt1 knockdown alleviates the cognitive improvement associated with HBO-PC. Freezing time for conditioned fear (left panel) and sensitized fear (right panel) in each group. $* P<0.05$ vs. sham, ${ }^{*} P<0.05$ vs. $\mathrm{HBO}+$ siRNA-C, $\# \#<<0.01$ vs. HBO + SiRNA-C.

Sirt1 knockdown prevents $\mathrm{HBO}-\mathrm{PC}$-induced elevation of pNF-H and DCX expression in the hippocampus of ischemic hemispheres

Hippocampal expression of pNF-H and DCX differed significantly between the four groups, as determined by immunohistochemistry (pNF-H: $F_{3,16}=84.57, P<0.01$ and DCX: $\left.F_{3,16}=42.36, P<0.01\right)$ and Western blotting (pNF-H: $F_{3,16}=14.99, P<0.01$ and DCX:
$F_{3,16}=11.97, \quad P<0.01$ ) (Fig. 5 and data not shown). A post hoc analysis revealed that $\mathrm{pNF}-\mathrm{H}$ and DCX levels were higher in the $\mathrm{HBO}+$ siRNA-C as compared to the siRNA-C group $(P<0.05)$, an effect that was abolished by Sirt1 knockdown $(P<0.05, \mathrm{HBO}+$ siRNA-C vs. HBO + siRNA-Sirt1). There was no significant difference between siRNA-Sirt1 and HBO + siRNA-Sirt1 groups in terms of pNF-H and DCX expression $(P>0.05)$.
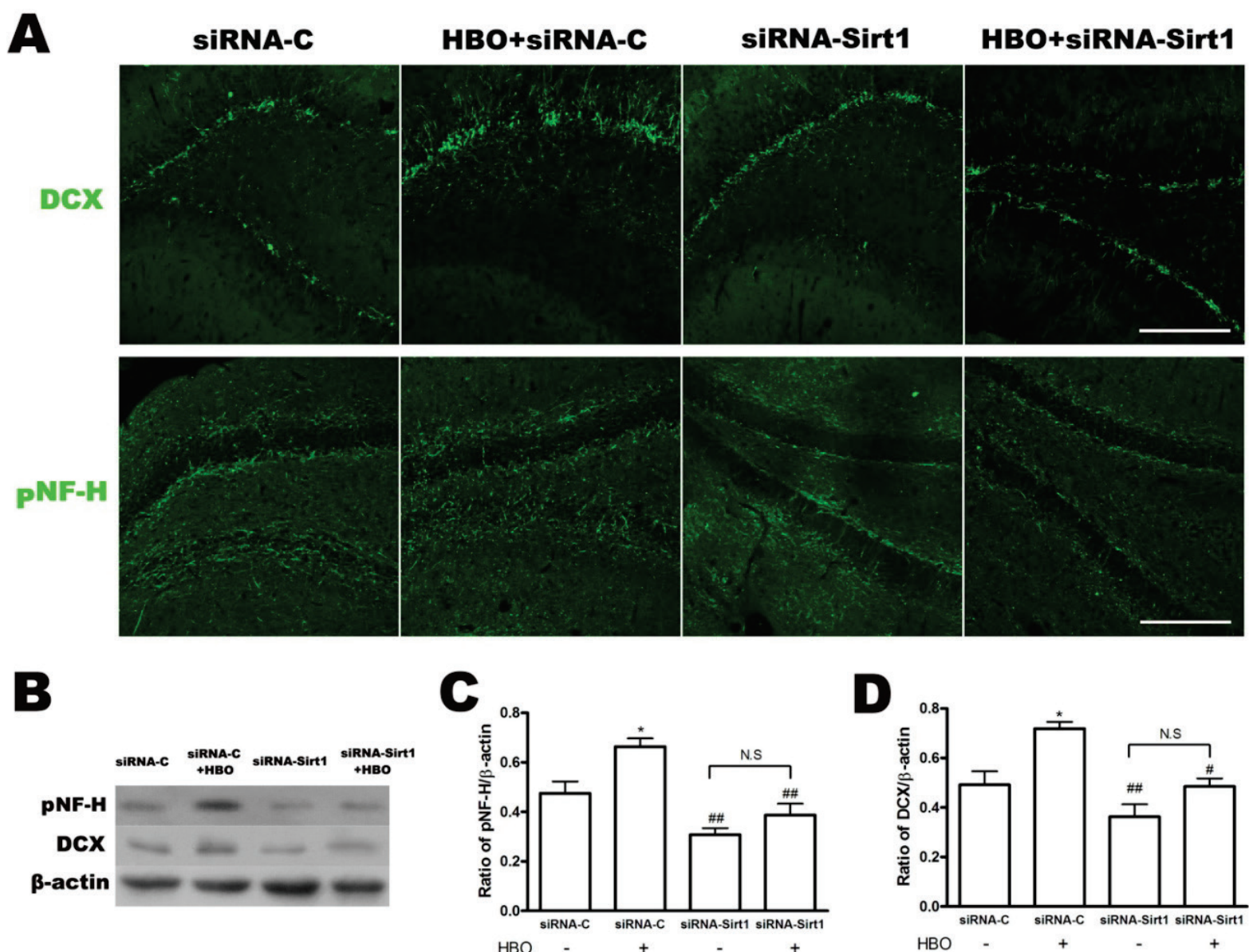

Fig. 5. Sirt1 knockdown inhibits pNF-H and DCX expression in the hippocampus of ischemic brain. Representative photomicrographs of pNF-H and DCX expression of each group as determined by immunolabeling (A) and Western blot analysis (B). Quantitative analysis of pNF-H (C) and DCX (D) expression levels. $* P<0.05$ vs. sham, ${ }^{\# \# ~} P<0.01$ vs. HBO + siRNA-C. Bar: $200 \mu \mathrm{m}$. 


\section{Discussion}

The present study investigated whether HBO-PC treatment can prevent cognitive deficits induced by focal cerebral ischemia, and whether Sirt1 is involved in this effect. The major findings were as follows: 1) HBO-PC $24 \mathrm{~h}$ before MCAO mitigated cognitive deficits; 2) DCX and pNF-H expression was upregulated in the ischemic brain after HBO-PC; and 3) Sirt1 knockdown abrogated the benefits conferred by HBO-PC. These results indicate that application of HBO-PC and increasing Sirtl levels can prevent neuronal injury caused by cerebral ischemia.

Cognitive deficits are a major factor affecting the life quality of ischemic stroke patients (Kwa et al. 1996). Ischemia can result in damage to the cerebral cortex (Saczynski et al. 2009) and hippocampus (Szabo et al. 2009, Tang et al. 2012). Reduction in the blood supply to the brain triggers various neuropathophysiological processes such as oxidative stress and inflammation that cause irreversible neuronal damage in non-ischemic regions (Butler et al. 2002, Block et al. 2005) as well as secondary damage that can affect cognition. HBO has demonstrated benefits in rodent models of ischemia induced by MCAO (Acka et al. 2007, Sun et al. 2011, $\mathrm{Mu}$ et al. 2013). HBO-PC has been similarly effective in human ischemia patients ( $\mathrm{Li}$ et al. 2011b). However, it is not known whether HPO-PC can improve cognitive deficits induced by cerebral ischemia.

Transient and permanent cerebral ischemia occur via distinct mechanisms (Yang et al. 2001), with a more severe inflammatory response observed in the latter (Zhou et al. 2013). It has been reported that HBO-PC is effective in transient but not permanent ischemic injury models (Xiong et al. 2000). We therefore used a transient cerebral ischemia model ( $1 \mathrm{~h}$ MCAO) in the present study. MCAO not only causes infarctions in the ipsilateral cerebral cortex, but also secondary retrograde neurodegeneration in the hippocampus (Wang et al. 2004) that result in neurological deficits, including cognitive impairment and inhibition of synaptic transmission (Yang et al. 2015).

To assess contextual memory impairment, we trained rats on a fear-conditioned task and evaluated conditioned and sensitized fear responses following MCAO with or without HBO-PC. Consistent with a previous study (Yabuki et al. 2015), we found that MCAO reduced freezing time for both types of fear response, whereas HBO-PC mitigated this effect. Both the ventral and dorsal hippocampal regions are important in the formation of conditioned fear memories (Esclassan et al. 2009); contextual fear conditioning requires gene transcription and protein synthesis in the hippocampus (Igaz et al. 2002). Moreover, neurogenesis and synaptic plasticity in the hippocampus is correlated with learning and memory (Drapeau et al. 2003). The mechanisms underlying secondary damage from ischemic stroke include retrograde axonal degeneration, neurotrophic dysregulation, and the upregulation of factors that inhibit neuronal growth (Yamashita et al. 2000).

To clarify the mechanistic basis for cognitive improvement by HBO-PC, we evaluated hippocampal expression of DCX and pNF-H. The former is a microtubule-associated protein in migrating neuroblasts that serves as a marker of immature neurons, whereas the latter is among the most highly phosphorylated proteins in the brain (Pant and Veeranna 1995); NF-H phosphorylation determines axonal caliber (Eyer and Peterson 1994), protects neurofilament proteins from proteolysis, and contributes to calcium buffering in axons (Krinks et al. 1988). Defects in NF-M/H phosphorylation in neurons can lead to blockage of axonal transport and cell death (Shea et al. 2004). We found that DCX and pNF-H levels were downregulated 14 days after MCAO; this reduction was alleviated by HBO-PC, suggesting that more neuroblasts were generated and neuroplasticity was increased by this treatment.

We also assessed conditioned and sensitized fear responses and hippocampal DCX and pNF-H expression upon Sirt1 knockdown. Sirt1 is a class III histone deacetylase that has been linked to neuronal plasticity and protection (Kim et al. 2007, Gao et al. 2010). For instance, Sirt1 was shown to protect neurons against ischemic injury induced by resveratrol (Wan et al. 2016) and regulate senescence-associated proteins in response to oxidative stress (Mattagajasingh et al. 2007, Storz 2011). Our previous study demonstrated that Sirt1 mediates ischemic tolerance by HBO-PC (Yan et al. 2013) as well as long-lasting neuroprotection in rat brain (Xue et al. 2016). Here we showed that Sirt1 knockdown blocked the improvement in memory and upregulation of DCX and pNF-H caused by HBO-PC, implying that Sirt1 contributes to HBO-PC-induced memory improvement by increasing neuroplasticity in the hippocampus.

Transient cerebral ischemia is known to stimulate neurogenesis in the dentate gyrus of adult rodents (Liu et al. 1998), which peaks on day 7 or 8 (Yagita et al. 2001, Takasawa et al. 2002); long-lasting neuroprotection can be observed for over 7 days after 
reperfusion (Liu et al. 2012, Eady et al. 2014). Newborn neurons contribute to the formation of hippocampaldependent memories (Bendel et al. 2005). However, the majority of these neurons are eliminated via apoptosis within several weeks (Kuhn et al. 2005); therefore, the therapeutic potential of neurogenesis induced by cerebral ischemia is low (Li et al. 2009). Stimulating neurogenesis and neuronal repair can help to overcome the low survival rate of neurons as a result of ischemia (Arvidsson et al. 2002).

In conclusion, our data suggest that HBO-PC promotes long-lasting improvements in memory following ischemia by preserving hippocampal neuroplasticity. These effects were mediated by Sirt1 activation. Further study is needed in order to clarify the detailed molecular mechanism of Sirt1 regulation in neurons and how this influences cognitive function.

\section{Conflict of Interest}

There is no conflict of interest.

\section{Acknowledgements}

This work was funded by the National Natural Science Foundation of China (nos. 81401109, 81571309, 81360193, and 81560214); the Project of Science and Technology of Social Development in Shaanxi Province (no. 2015SF005); the Natural Fund Project (no. 1208RJZA110); and Health Industry Research Project of Gansu Province (no. GSWSKY2015-01).

\begin{abstract}
Abbreviations
DCX, doublecortin; HBO-PC, hyperbaric oxygen preconditioning; MCAO, middle cerebral artery occlusion; pNF-H, phosphorylated neurofilament heavy polypeptide; siRNA, short interfering RNA; Sirt1, sirtuin 1.
\end{abstract}

\section{References}

ACKA G, SEN A, CANAKCI Z, YILDIZ S, AKIN A, UZUN G, CERMIK H, YILDIRIM I, KOKPINAR S: Effect of combined therapy with hyperbaric oxygen and antioxidant on infarct volume after permanent focal cerebral ischemia. Physiol Res 56: 369-373, 2007.

AMANTEA D, NAPPI G, BERNARDI G, BAGETTA G, CORASANITI MT: Post-ischemic brain damage: pathophysiology and role of inflammatory mediators. FEBS J 276: 13-26, 2008.

ARVIDSSON A, COLLIN T, KIRIK D, KOKAIA Z, LINDVALL O: Neuronal replacement from endogenous precursors in the adult brain after stroke. Nat Med 8: 963-970, 2002.

BENDEL O, BUETERS T, VON EULER M, OVE OGREN S, SANDIN J, VON EULER G: Reappearance of hippocampal CA1 neurons after ischemia is associated with recovery of learning and memory. $J$ Cereb Blood Flow Metab 25: 1586-1595, 2005.

BIAN H, HU Q, LIANG X, CHEN D, LI B, TANG J, ZHANG JH: Hyperbaric oxygen preconditioning attenuates hemorrhagic transformation through increasing PPARgamma in hyperglycemic MCAO rats. Exp Neurol 265: 22-29, 2015.

BLOCK F, DIHNE M, LOOS M: Inflammation in areas of remote changes following focal brain lesion. Prog Neurobiol 75: 342-365, 2005.

BOUET V, FRERET T, TOUTAIN J, DIVOUX D, BOULOUARD M, SCHUMANN-BARD P: Sensorimotor and cognitive deficits after transient middle cerebral artery occlusion in the mouse. Exp Neurol 203: 555-567, 2007.

BUTLER TL, KASSED CA, SANBERG PR, WILLING AE, PENNYPACKER KR: Neurodegeneration in the rat hippocampus and striatum after middle cerebral artery occlusion. Brain Res 929: 252-260, 2002.

CHAN PH: Role of oxidants in ischemic brain damage. Stroke 27: 1124-1129, 1996.

CHEN C, HU Q, YAN J, YANG X, SHI X, LEI J, CHEN L, HUANG H, HAN J, ZHANG JH, ZHOU C: Early inhibition of HIF-1alpha with small interfering RNA reduces ischemic-reperfused brain injury in rats. Neurobiol Dis 33: 509-517, 2009.

CHEN H, YOSHIOKA H, KIM GS, JUNG JE, OKAMI N, SAKATA H, MAIER CM, NARASIMHAN P, GOEDERS CE, CHAN PH: Oxidative stress in ischemic brain damage: mechanisms of cell death and potential molecular targets for neuroprotection. Antioxid Redox Signal 14: 1505-1517, 2011. 
DEB P, SHARMA S, HASSAN KM: Pathophysiologic mechanisms of acute ischemic stroke: an overview with emphasis on therapeutic significance beyond thrombolysis. Pathophysiology 17: 197-218, 2010.

DRAPEAU E, MAYO W, AUROUSSEAU C, LE MOAL M, PIAZZA PV, ABROUS DN: Spatial memory performances of aged rats in the water maze predict levels of hippocampal neurogenesis. Proc Natl Acad Sci US A 100: 14385-14390, 2003.

DU Y, ZHANG X, JI H, LIU H, LI S, LI L: Probucol and atorvastatin in combination protect rat brains in MCAO model: upregulating Peroxiredoxin2, Foxo3a and Nrf2 expression. Neurosci Lett 509: 110-115, 2012.

EADY TN, KHOUTOROVA L, OBENAUS A, MOHD-YUSOF A, BAZAN NG, BELAYEV L: Docosahexaenoic acid complexed to albumin provides neuroprotection after experimental stroke in aged rats. Neurobiol Dis 62 : $1-7,2014$.

ESCLASSAN F, COUTUREAU E, Di SCALA G, MARCHAND AR: Differential contribution of dorsal and ventral hippocampus to trace and delay fear conditioning. Hippocampus 19: 33-44, 2009.

EYER J, PETERSON A: Neurofilament-deficient axons and perikaryal aggregates in viable transgenic mice expressing a neurofilament-beta-galactosidase fusion protein. Neuron 12: 389-405, 1994.

GAO J, WANG WY, MAO YW, GRÄFF J, GUAN JS, PAN L, MAK G, KIM D, SU SC, TSAI LH: A novel pathway regulates memory and plasticity via SIRT1 and miR-134. Nature 466: 1105-1109, 2010.

IGAZ LM, VIANNA MR, MEDINA JH, IZQUIERDO I: Two time periods of hippocampal mRNA synthesis are required for memory consolidation of fear-motivated learning. J Neurosci 22: 6781-6789, 2002.

JAFARI Z, ESMAILI M, DELBARI A, MEHRPOUR M, MOHAJERANI MH: Auditory temporal processing deficits in chronic stroke: a comparison of brain damage lateralization effect. J Stroke Cerebrovasc Dis 25: 1403-1410, 2016.

JIN R, YANG G, LI G: Inflammatory mechanisms in ischemic stroke: role of inflammatory cells. J Leukoc Biol 87: 779-789, 2010.

KIM D, NGUYEN MD, DOBBIN MM, FISCHER A, SANANBENESI F, RODGERS JT, DELALLE I, BAUR JA, SUI G, ARMOUR SM, PUIGSERVER P, SINCLAIR DA, TSAI LH: SIRT1 deacetylase protects against neurodegeneration in models for Alzheimer's disease and amyotrophic lateral sclerosis. EMBO $J$ 26: 3169-3179, 2007.

KRAFT A, IRLBACHER K, FINKE K, KAUFMANN C, KEHRER S, LIEBERMANN D, BUNDESEN C, BRANDT SA: Dissociable spatial and non-spatial attentional deficits after circumscribed thalamic stroke. Cortex 64: 327-342, 2015.

KRINKS MH, KLEE CB, PANT HC, GAINER H: Identification and quantification of calcium-binding proteins in squid axoplasm. J Neurosci 8: 2172-2182, 1998.

KUHN HG, BIEBL M, WILHELM D, LI M, FRIEDLANDER RM, WINKLER J: Increased generation of granule cells in adult Bcl-2-overexpressing mice: a role for cell death during continued hippocampal neurogenesis. Eur $J$ Neurosci 22: 1907-1915, 2005.

KURE CE, ROSENFELDT FL, SCHOLEY AB, PIPINGAS A, KAYE DM, BERGIN PJ, CROFT KD, WESNES KA, MYERS SP, STOUGH C: Relationships among cognitive function and cerebral blood flow, oxidative stress, and inflammation in older heart failure patients. J Card Fail 22: 548-559, 2016.

KWA VI, LIMBURG M, DE HAAN RJ: The role of cognitive impairment in the quality of life after ischaemic stroke. J Neurol 243: 599-604, 1996.

LI M, ZHANG X, CUI L, YANG R, WANG L, LIU L, DU W: The neuroprotection of oxymatrine in cerebral ischemia/reperfusion is related to nuclear factor erythroid 2-related factor 2 (nrf2)-mediated antioxidant response: role of nrf2 and hemeoxygenase-1 expression. Biol Pharm Bull 34: 595-601, 2011.

LI WL, CAI HH, WANG B, CHEN L, ZHOU QG, LUO CX, LIU N, DING XS, ZHU DY: Chronic fluoxetine treatment improves ischemia-induced spatial cognitive deficits through increasing hippocampal neurogenesis after stroke. J Neurosci Res 87: 112-122, 2009.

LI Y, DONG H, CHEN M, LIU J, YANG L, CHEN S, XIONG L: Preconditioning with repeated hyperbaric oxygen induces myocardial and cerebral protection in patients undergoing coronary artery bypass graft surgery: a prospective, randomized, controlled clinical trial. J Cardiothorac Vasc Anesth 25: 908-916, 2011. 
LIU H, ZHANG X, DU Y, JI H, LI S, LI L, XING Y, ZHANG X, DONG L, WANG C, ZHAO K, JI Y, CAO X: Leonurine protects brain injury by increased activities of UCP4, SOD, CAT and Bcl-2, decreased levels of MDA and Bax, and ameliorated ultrastructure of mitochondria in experimental stroke. Brain Res 1474: 73-81, 2012.

LIU J, SOLWAY K, MESSING RO, SHARP FR: Increased neurogenesis in the dentate gyrus after transient global ischemia in gerbils. $J$ Neurosci 18: 7768-7778, 1998.

MASSA MS, WANG N, BICKERTON WL, DEMEYERE N, RIDDOCH MJ, HUMPHREYS GW: On the importance of cognitive profiling: a graphical modelling analysis of domain-specific and domain-general deficits after stroke. Cortex 71: 190-204, 2015.

MATTAGAJASINGH I, KIM CS, NAQVI A, YAMAMORI T, HOFFMAN TA, JUNG SB, DERICCO J, KASUNO K, IRANI K: SIRT1 promotes endothelium-dependent vascular relaxation by activating endothelial nitric oxide synthase. Proc Natl Acad Sci U S A 104: 14855-14860, 2007.

MEYER S, KESSNER SS, CHENG B, BÖNSTRUP M, SCHULZ R, HUMMEL FC, DE BRUYN N, PEETERS A, VAN PESCH V, DUPREZ T, SUNAERT S, SCHROOTEN M, FEYS H, GERLOFF C, THOMALLA G, THIJS V, VERHEYDEN G: Voxel-based lesion-symptom mapping of stroke lesions underlying somatosensory deficits. Neuroimage Clin 10: 257-266, 2015.

MINAMI M, KATAYAMA T, SATOH M: Brain cytokines and chemokines: roles in ischemic injury and pain. J Pharmacol Sci 100: 461-470, 2006.

MU J, OSTROWSKI RP, SOEJIMA Y, ROLLAND WB, KRAFFT PR, TANG J, ZHANG JH: Delayed hyperbaric oxygen therapy induces cell proliferation through stabilization of cAMP responsive element binding protein in the rat model of MCAo-induced ischemic brain injury. Neurobiol Dis 51: 133-143, 2013.

NIE H, PENG Z, LAO N, WANG H, CHEN Y, FANG Z, HOU W, GAO F, LI X, XIONG L, TAN Q: Rosmarinic acid ameliorates PTSD-like symptoms in a rat model and promotes cell proliferation in the hippocampus. Prog Neuropsychopharmacol Biol Psychiatry 51: 16-22, 2014.

NIIZUMA K, ENDO H, CHAN PH: Oxidative stress and mitochondrial dysfunction as determinants of ischemic neuronal death and survival. J Neurochem 109 (Suppl 1): 133-138, 2009.

PANT HC, VEERANNA: Neurofilament phosphorylation. Biochem Cell Biol 73: 575-592, 1995.

QIAO H, ZHANG X, ZHU C, DONG L, WANG L, ZHANG X, XING Y, WANG C, JI Y, CAO X: Luteolin downregulates TLR4, TLR5, NF-kappaB and p-p38MAPK expression, upregulates the p-ERK expression, and protects rat brains against focal ischemia. Brain Res 1448: 71-81, 2012.

RUSSO T, FELZANI G, MARINI C: Stroke in the very old: a systematic review of studies on incidence, outcome, and resource use. J Aging Res 2011: 108785, 2011.

SACZYNSKI JS, SIGURDSSON S, JONSDOTTIR MK, EIRIKSDOTTIR G, JONSSON PV, GARCIA ME, KJARTANSSON O, LOPEZ O, VAN BUCHEM MA, GUDNASON V, LAUNER LJ: Cerebral infarcts and cognitive performance: importance of location and number of infarcts. Stroke 40: 677-682, 2009.

SAKAI N, YANAI K, RYU JH, NAGASAWA H, HASEGAWA T, SASAKI T, KOGURE K, WATANABE T: Behavioral studies on rats with transient cerebral ischemia induced by occlusion of the middle cerebral artery. Behav Brain Res 77: 181-188, 1996.

SHEA TB, ZHENG YL, ORTIZ D, PANT HC: Cyclin-dependent kinase 5 increases perikaryal neurofilament phosphorylation and inhibits neurofilament axonal transport in response to oxidative stress. J Neurosci Res 76: 795-800, 2004.

SOEJIMA Y, HU Q, KRAFFT PR, FUJII M, TANG J, ZHANG JH: Hyperbaric oxygen preconditioning attenuates hyperglycemia-enhanced hemorrhagic transformation by inhibiting matrix metalloproteinases in focal cerebral ischemia in rats. Exp Neurol 247: 737-743, 2013.

STORZ P: Forkhead homeobox type O transcription factors in the responses to oxidative stress. Antioxid Redox Signal 14: 593-605, 2011.

SUN L, STRELOW H, MIES G, VELTKAMP R: Oxygen therapy improves energy metabolism in focal cerebral ischemia. Brain Res 1415: 103-108, 2011.

SZABO K, FORSTER A, JAGER T, KERN R, GRIEBE M, HENNERICI MG, GASS A: Hippocampal lesion patterns in acute posterior cerebral artery stroke: clinical and MRI findings. Stroke 40: 2042-2045, 2009. 
TAKASAWA K, KITAGAWA K, YAGITA Y, SASAKI T, TANAKA S, MATSUSHITA K, OHSTUKI T, MIYATA T, OKANO H, HORI M, MATSUMOTO M: Increased proliferation of neural progenitor cells but reduced survival of newborn cells in the contralateral hippocampus after focal cerebral ischemia in rats. $J$ Cereb Blood Flow Metab 22: 299-307, 2002.

TANG X, WANG C, XIA L, ZHU W, ZHAO L: Volumetric MRI and 1H MRS study of hippocampus in unilateral MCAO patients: relationship between hippocampal secondary damage and cognitive disorder following stroke. Eur J Radiol 81: 2788-2793, 2012.

WAN D, ZHOU Y, WANG K, HOU Y, HOU R, YE X: Resveratrol provides neuroprotection by inhibiting phosphodiesterases and regulating the cAMP/AMPK/SIRT1 pathway after stroke in rats. Brain Res Bull 121: 255-262, 2016.

WANG Q, PENG Y, CHEN S, GOU X, HU B, DU J, LU Y, XIONG L: Pretreatment with electroacupuncture induces rapid tolerance to focal cerebral ischemia through regulation of endocannabinoid system. Stroke 40: 2157 2164, 2009.

WANG W, REDECKER C, BIDMON HJ, WITTE OW: Delayed neuronal death and damage of GDNF family receptors in CA1 following focal cerebral ischemia. Brain Res 1023: 92-101, 2004.

XIONG L, ZHU Z, DONG H, HU W, HOU L, CHEN S: Hyperbaric oxygen preconditioning induces neuroprotection against ischemia in transient not permanent middle cerebral artery occlusion rat model. Chin Med J (Engl) 113: 836-839, 2000.

XUE F, HUANG JW, DING PY, ZANG HG, KOU ZJ, LI T, FAN J, PENG ZW, YAN WJ: Nrf2/antioxidant defense pathway is involved in the neuroprotective effects of Sirtl against focal cerebral ischemia in rats after hyperbaric oxygen preconditioning. Behav Brain Res 309: 1-8, 2016.

YABUKI Y, SHINODA Y, IZUMI H, IKUNO T, SHIODA N, FUKUNAGA K: Dehydroepiandrosterone administration improves memory deficits following transient brain ischemia through sigma-1 receptor stimulation. Brain Res 1622: 102-113, 2015.

YAGITA Y, KITAGAWA K, OHTSUKI T, TAKASAWA KI, MIYATA T, OKANO H, HORI M, MATSUMOTO M: Neurogenesis by progenitor cells in the ischemic adult rat hippocampus. Stroke 32: 1890-1896, 2001.

YAMASHITA K, KATAOKA Y, SAKURAI-YAMASHITA Y, SHIGEMATSU K, HIMENO A, NIWA M, TANIYAMA K: Involvement of glial endothelin/nitric oxide in delayed neuronal death of rat hippocampus after transient forebrain ischemia. Cell Mol Neurobiol 20: 541-551, 2000.

YAN W, ZHANG H, BAI X, LU Y, DONG H, XIONG L: Autophagy activation is involved in neuroprotection induced by hyperbaric oxygen preconditioning against focal cerebral ischemia in rats. Brain Res 1402: 109-121, 2011.

YAN W, FANG Z, YANG Q, DONG H, LU Y, LEI C, XIONG L: SirT1 mediates hyperbaric oxygen preconditioninginduced ischemic tolerance in rat brain. J Cereb Blood Flow Metab 33: 396-406, 2013.

YANG LC, GUO H, ZHOU H, SUO DQ, LI WJ, ZHOU Y, ZHAO Y, YANG WS, JIN X: Chronic oleoylethanolamide treatment improves spatial cognitive deficits through enhancing hippocampal neurogenesis after transient focal cerebral ischemia. Biochem Pharmacol 94: 270-281, 2015.

YANG Y, LI Q, MIYASHITA H, YANG T, SHUAIB A: Different dynamic patterns of extracellular glutamate release in rat hippocampus after permanent or 30-min transient cerebral ischemia and histological correlation. Neuropathology 21: 181-187, 2001.

ZHOU W, LIESZ A, BAUER H, SOMMER C, LAHRMANN B, VALOUS N, GRABE N, VELTKAMP R: Postischemic brain infiltration of leukocyte subpopulations differs among murine permanent and transient focal cerebral ischemia models. Brain Pathol 23: 34-44, 2013. 